\title{
Percepções sobre as ações das redes públicas de ensino durante a pandemia
}

\author{
Jairo Campos dos Santositi \\ Prefeitura da cidade do Rio de Janeiro, Rio de Janeiro, RJ, Brasil \\ Luiza Alves de Oliveiraii(t) \\ Universidade Federal Rural do Rio de Janeiro, Rio de Janeiro, RJ, Brasil
}

\begin{abstract}
Resumo
O objetivo deste trabalho é captar a percepção dos profissionais de Educação Básica sobre as ações de suas redes de ensino durante a Covid-19. Dessa forma, através de uma análise quantitativa dos dados colhidos por uma pesquisa exploratória das respostas a um questionário aplicado a 123 profissionais, durante o período de 01/04/2020 a 01/07/2020, observou-se que, embora a percepção dos profissionais reconheça a efetiva participação de suas redes de ensino para que não ocorra interrupção das atividades com os alunos, um percentual relevante de professores interrompeu completamente suas atividades e os que continuaram atuando realizaram atividades de maneira autônoma, sem direcionamento e sem ações coordenadas. Registrou-se que estudos futuros poderão evidenciar com mais clareza os danos que a situação aqui estudada causará nesta geração de alunos.
\end{abstract}

Palavras-chave

Educação. Percepção. Professores. Pandemia. Covid-19.

\section{Perceptions about the actions of public schools during the pandemic}

\begin{abstract}
The objective of this work is to capture the perception of the professionals of Basic Education about the actions of their educational systems during Covid-19. Thus, through a quantitative analysis of the data collected by exploratory research, through responses to a questionnaire applied to 123 professionals, during the period from 01/04/2020 to $01 / 07 / 2020$, we observed that, although the perception of professionals recognizes the effective participation of their educational systems so that there is no interruption of activities with students, a relevant percentage of teachers completely interrupted their activities and those who continued to work, performed activities autonomously, without direction and without coordinated actions. We have recorded that future studies may show more clearly the damage that the situation studied here will cause in this generation of students.
\end{abstract}

\section{Keywords}

Education. Perception. Teachers. Pandemic. Covid-19. 


\title{
Percepciones sobre las acciones de las escuelas públicas durante la pandemia
}

\begin{abstract}
Resumen
El objetivo de este trabajo es capturar la percepción de los profesionales de la Educación Básica sobre las acciones de sus redes educativas durante el Covid-19. Así, a través de un análisis cuantitativo de los datos recogidos por una encuesta exploratoria de respuestas a un cuestionario aplicado a 123 profesionales, durante el período del 01/04/2020 al 01/07/2020, se observó que, si bien la percepción de los profesionales reconoce la participación efectiva de sus redes docentes para que no haya interrupción de las actividades con los estudiantes, un porcentaje relevante de docentes interrumpió por completo sus actividades y los que continuaron trabajando realizaron actividades de forma autónoma, sin dirección y sin acciones coordinadas. Se constató que estudios futuros pueden mostrar más claramente el daño que la situación aquí estudiada causará en esta generación de estudiantes.
\end{abstract}

Palabras clave

Educación. Percepción. Profesores. Pandemia. Covid-19.

\section{Introdução}

No primeiro trimestre de 2020, o mundo foi assolado por uma pandemia (Covid-19) que terminou por alterar todo o comportamento humano relacionado a atividades em grupo, afetando essencialmente o trabalho escolar. No Brasil, o cenário ficou imensamente mais caótico, pois a falta de orientações precisas, de um bom gerenciamento da crise e de unidade entre os entes federativos colocou a população, especialmente a mais pobre, numa situação de dúvidas e incertezas, cercada pela má informação e pela baixa assistência de ações governamentais. Esse cenário fez com que as pessoas, que já viviam processos de exclusão social e econômica, mergulhassem em uma condição de vida mais precarizada, de acordo com o estudo de Macedo, Ornellas e Bomfim (2020), que trata da população subalternizada no Brasil em tempo da pandemia da Covid-19. Ainda sobre esse contexto, Campos (2020, p. 3) afirma que:

\footnotetext{
O presidente da república (Jair Bolsonaro) já repetiu, várias vezes, que as mortes serão inevitáveis e que as pessoas deverão aceitar passivamente essa fatalidade. A insistência com que vem repetindo esse desatino - como uma fatalidade - indica que Bolsonaro é dominado pela pulsão de morte. Seu apego às armas e à violência são sintomas de um caráter perverso, insensível diante do sofrimento humano. Para compreender a posição negacionista do presidente diante da pandemia, é fundamental também considerar outro traço forte em sua personalidade - o egocentrismo exacerbado - que se revela na fixação em um projeto pessoal e familiar de poder.
}

Educ. Form., Fortaleza, v. 6, n. 3, e5412, set./dez. 2021

DOI: https://doi.org/10.25053/redufor.v6i2.5412

https://revistas.uece.br/index.php/redufor/index 
Dentro do cenário traçado acima, encontra-se a educação pública brasileira, que há anos carrega diversos problemas, muitos deles relacionados à qualidade, estrutura, desempenho dos alunos, precarização do trabalho docente, enfim, uma diversidade de situações que impedem sobremaneira seu desenvolvimento para um nível que fosse, no mínimo, satisfatório para todos os cidadãos, pois, como menciona Silva (2020, s.p.):

\begin{abstract}
A precarização da educação pública é consequência das políticas neoliberais implementadas nas últimas duas décadas. Se, por um lado, os anseios empresariais foram atendidos, docentes e estudantes, por outro, amargaram baixos salários, más condições de ensino e aprendizado, segregação e outros efeitos danosos. Aos empresários, o lucro e o bem-estar; aos trabalhadores e aos estudantes, perda de direitos e vida precária.
\end{abstract}

Se pesquisas na área de educação são de execuções complexas, pois é um campo com diferentes características, cenários, problemas e orientações, entre outros aspectos, realizarmos uma pesquisa durante um período de isolamento social, por si só, já passa a ser um limitador. Contudo, a urgência por respostas a questões relacionadas a como os professores de escolas públicas estariam vivenciando a (in)gerência de ações político-pedagógicas diante do isolamento social compulsório se constituiu como agente motivador para buscarmos caminhos teóricos e metodológicos para realizarmos a presente pesquisa em um cenário de estranhamento e incertezas.

Logo, tudo ficou diferente ou, como menciona Santana Filho (2020, p. 5):

A docência e a educação escolar estão abaladas. A pandemia, ao nos isolar uns dos outros, estudantes, professores, pedagogos, gestores públicos e privados, abala a dinâmica da escola: seu sentido baseado na convivência e compartilhamento de ideias e saberes, na transmissão de conteúdos consolidados e conduzida por práticas seculares encontra-se revirado. Que fazer?

Assim, captar, "dentro do possível", em um cenário pandêmico, a percepção dos profissionais de educação quanto às ações implementadas (ou não) em suas redes de ensino se traduziu através de um levantamento exploratório, por meio de um questionário estruturado com perguntas fechadas. Tal procedimento permitiu a coleta de dados necessários para o objetivo aqui proposto. Para tanto, buscamos os mecanismos existentes (redes sociais compostas por grupos de professores e endereços eletrônicos)

Educ. Form., Fortaleza, v. 6, n. 3, e5412, set./dez. 2021

DOI: https://doi.org/10.25053/redufor.v6i2.5412

https://revistas.uece.br/index.php/redufor/index 
com a finalidade de termos contato com os profissionais de educação que potencialmente poderiam participar da pesquisa (amostra).

Como o objetivo deste trabalho é captar qual a percepção dos profissionais de Educação Básica sobre as ações de suas redes de ensino durante a pandemia, iniciamos o estudo traçando o cenário das atividades de educação na cidade do Rio de Janeiro, a partir do início da pandemia gerada pela Covid-19 (março de 2020), e seguimos até o mês de julho de 2020, data em que encerramos a pesquisa com o questionário. Ou seja, a coleta de dados foi realizada durante cinco meses e referenciou- -se nas ações oficiais sobre as aulas e demais atividades das escolas dentro do município do Rio de Janeiro, fosse pelo ente federal, estadual ou municipal.

Em avanço, delineamos o grupo de participantes desta pesquisa, isto é, as características dos profissionais de educação, definindo as suas atividades na escola, o tempo de atividade profissional e sua rede de ensino (federal, estadual ou municipal).

Já para traçarmos os caminhos para a análise fundamental deste trabalho, seguimos com três partes importantes, que são: informações gerais sobre as atividades executadas pelos profissionais de educação durante o período da pandemia; realização/participação dos profissionais em algum curso ou capacitação em Educação a Distância (EaD) para minimizar os impactos da pandemia nos processos educacionais; e existência de apoio da rede de ensino a esses profissionais para a realização de atividades próprias da docência.

Após essas etapas, avançamos com a análise exploratória das informações apresentadas, com a intenção de traçarmos conclusões sobre o objetivo deste trabalho, dentro dos limites possíveis para a sua realização, além de registrarmos o potencial do que está sendo apresentado de maneira que se possibilite contribuir para ações ou novos estudos.

Em prosseguimento às ideias introdutórias deste artigo, apresentamos, a seguir, o cenário no qual se desenvolveu o presente estudo. 


\section{0 cenário}

Em uma situação com proporção jamais vivida, a cidade do Rio de Janeiro precisou impor um isolamento social com a finalidade de diminuir o contágio pela Covid-19. Um dos pontos cruciais estabelecidos pelo isolamento social foi a interrupção das atividades presenciais nas redes de educação da cidade; como existem instituições públicas de Educação Básica dos três entes federativos, apresentamos aqui o cenário traçado por cada uma dessas redes de ensino.

Observamos, dessa forma, que o cenário para a continuidade das atividades educacionais não presenciais foi definido através de pareceres ou deliberações dos Conselhos de Educação (federal, estadual e municipal) para cada ente federativo, conforme apresentado a seguir de maneira resumida, mas que atende ao planejado para este trabalho.

\subsection{Rede federal de ensino}

Para a rede federal, o documento norteador foi o Parecer do Conselho Nacional de Educação (CNE)/ Conselho Pleno (CP) ํㅜ 5, de 28 de abril de 2020, cujo conteúdo foi dividido nas seguintes partes:

I Histórico - que trata das origens da pandemia e sua circulação pelo mundo até chegar ao Brasil, as manifestações da Organização Mundial da Saúde (OMS), além de registrar as ações e orientações iniciais do Ministério da Educação, do CNE, dos estados e municípios sobre a pandemia;

II Análise - que interpreta o cenário da doença no Brasil e seus impactos nas atividades de educação, demonstrando os diversos desafios que serão enfrentados dentro das desigualdades estruturais existentes, explorando de maneira especial os direitos e objetivos de aprendizagem, o calendário escolar e carga horária mínima a ser cumprida, a competência para gestão do calendário escolar, a reorganização do calendário escolar, as atividades de EaD, entre outras ações.

Por ser um parecer do CNE, a abrangência foi geral, ou seja, atingiu todos os níveis educacionais. 


\subsection{Rede estadual de ensino}

No estado do Rio de Janeiro, o Conselho Estadual de Educação (CEE) publicou a Deliberação CEE № 376, de 23 de março de 2020, que traçou de forma mais objetiva o estabelecimento de orientações para as instituições integrantes do Sistema Estadual de Ensino do estado do Rio de Janeiro, sobre o desenvolvimento das atividades escolares não presenciais, em caráter de excepcionalidade e temporalidade, enquanto permanecerem as medidas de isolamento, previstas pelas autoridades estaduais, na prevenção e combate ao coronavírus - Covid-19.

\subsection{Rede municipal de ensino}

A rede municipal de ensino do Rio de Janeiro, através do Conselho Municipal de Educação (CME), tornou pública a Deliberação E/CME № 39, de 2 de abril de 2020, que orienta as instituições do sistema municipal de ensino do Rio de Janeiro sobre a realização de atividades escolares em regime especial domiciliar, em caráter excepcional, no período em que permanecerem em isolamento social fixado pelas autoridades municipais e pela comunidade médico-científica, em razão da necessidade de prevenção e combate à Covid-19.

Percebemos que as ações possuem em comum o fato de se resguardar a vida e impedir a circulação do vírus. No entanto, essa postura terminou por afetar a atividade pedagógica nos três entes federativos e, em especial, a atividade profissional do professor, pois o trabalho docente é definido tanto por sua contingência como também por uma estrutura com certa estabilidade (GAUTHIER; BISSONNETTE; BOCQUILLON, 2021).

Ora, mesmo com uma legislação que respaldasse a impossibilidade de aulas presenciais, a grande maioria de professores se deparou com dilemas impensáveis, já que os pareceres dos conselhos também apontavam para a necessidade de ações para se garantir contato com os alunos através de atividades remotas. Se, por um lado, não se questionava tal premência prevista legalmente, as redes de ensino pareciam não saber como orientar seus professores para cumprir tal exigência. Assim, mais uma vez, os docentes buscaram, por si, alternativas possíveis para tais urgências e criaram 
percepções sobre o cenário que se descortinava diante de uma crise sanitária mundial. São justamente essas compreensões que buscamos identificar e analisar neste estudo. Para tal, na seção seguinte, caracterizamos o grupo de professores participantes da pesquisa.

\section{Características do grupo de participantes da pesquisa}

Inicialmente, para uma melhor compreensão dos aspectos limitadores que influenciaram a coleta de dados para este estudo, é importante verificar que o contato com as pessoas ficou restrito. Portanto, para que os profissionais de educação respondessem ao questionário proposto, desenvolvido no aplicativo Google Docs, foi necessário o uso das redes sociais disponíveis, mas também encontrar interesse e disposição para que eles participassem da pesquisa espontaneamente.

Procuramos disponibilizar o questionário, em grupos de profissionais da educação da cidade do Rio de Janeiro no Facebook, na maior quantidade possível. Entretanto, por ser um ato espontâneo, delimitamos um período para que o questionário ficasse exposto nos grupos e, ao término desse prazo, realizamos a análise com o conteúdo de questionários respondidos.

É importante registrarmos que, de acordo com Doxsey e De Riz (2002/2003, p. 46-47):

O bom senso não é suficiente para determinar o tamanho da amostra em pesquisas quantitativas. É necessário utilizar as fórmulas, evitando regras simplistas pelas quais o pesquisador aplica uma porcentagem $\mathrm{X}$ ao número total população (universo) para calcular a amostra. Via de regra, evita-se [sic] estudos quantitativos (exploratórios ou descritivos) com menos de 30 casos. Dependendo do estudo, muitas vezes, apenas um grupo será insuficiente para a pesquisa quantitativa ou qualitativa.

Esclarecemos, assim, que o questionário ficou disponível para respostas durante o período de 01/04/2020 a 01/07/2020 e foram obtidas 123 participações de profissionais de educação, com as seguintes características básicas, definidas para este trabalho: 
Gráfico 1 - Atividade na escola

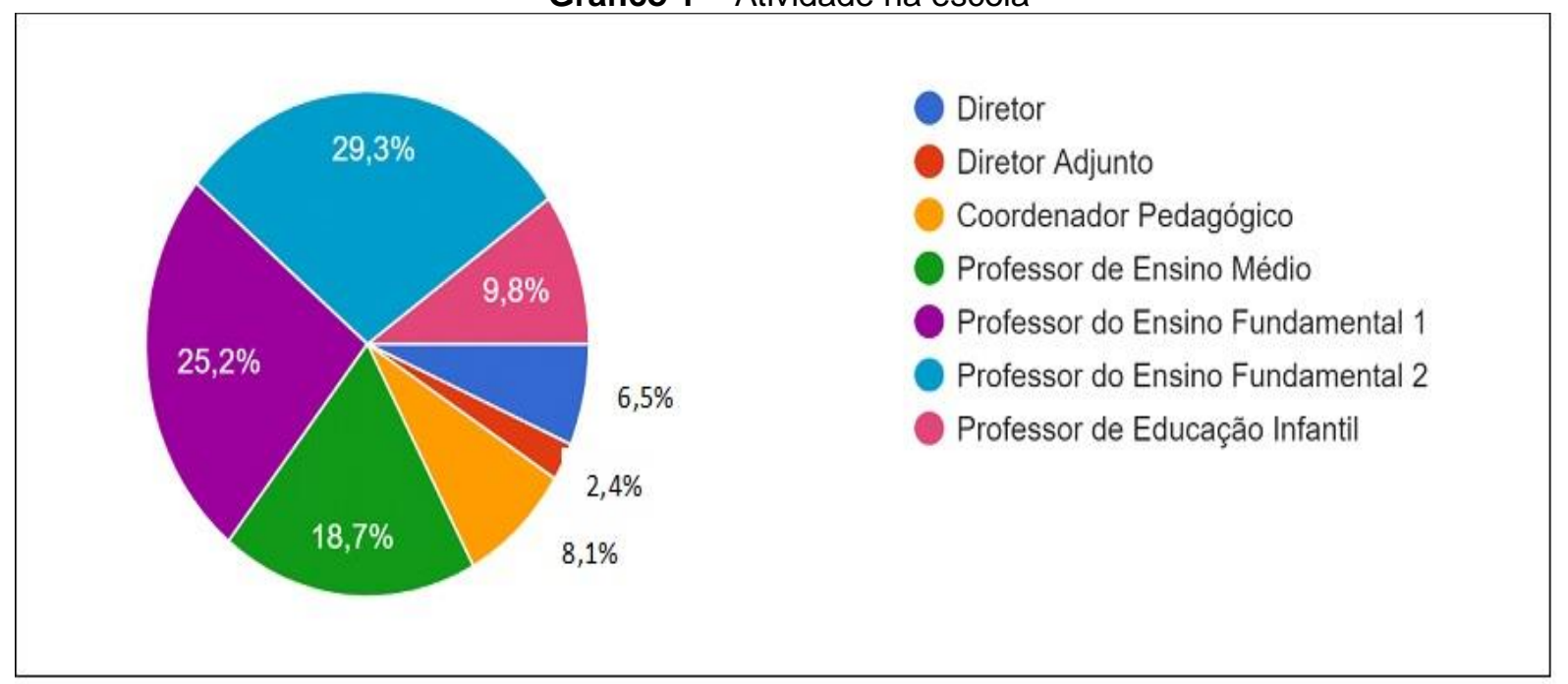

Fonte: Elaborado pelos autores com base nos dados da pesquisa (2020).

Observamos acima que a grande maioria dos respondentes nesta pesquisa (83\%) é composta por profissionais de educação que está exercendo suas atividades, dentro de sala de aula, como professor na Educação Básica.

Gráfico 2 - Tempo de atividade na educação pública

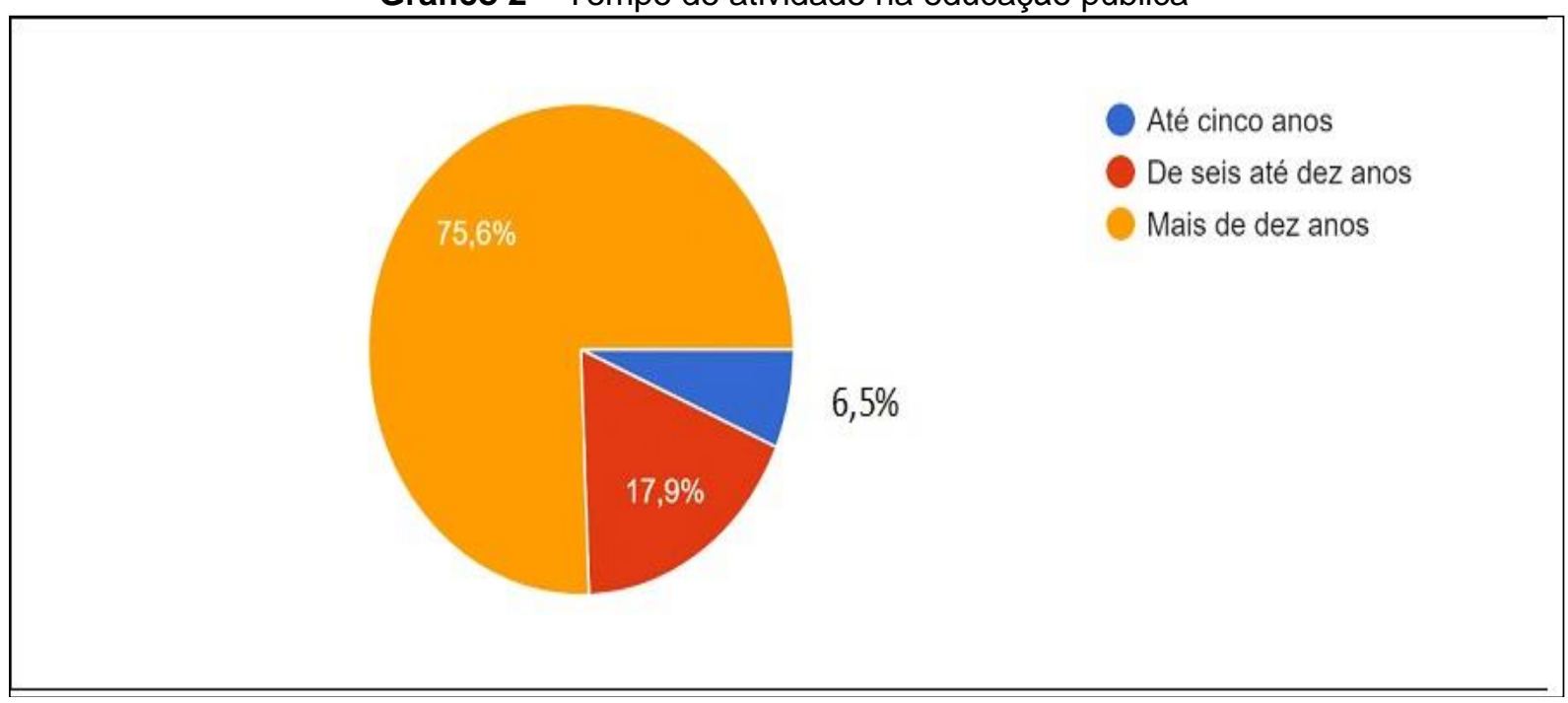

Fonte: Elaborado pelos autores com base nos dados da pesquisa (2020).

Outra característica importante que identificamos, conforme o Gráfico 2, é que a maior parte dos participantes da pesquisa possui mais de dez anos de atividade na educação pública.

Educ. Form., Fortaleza, v. 6, n. 3, e5412, set./dez. 2021

DOI: https://doi.org/10.25053/redufor.v6i2.5412

https://revistas.uece.br/index.php/redufor/index 
Gráfico 3 - Rede pública de atuação

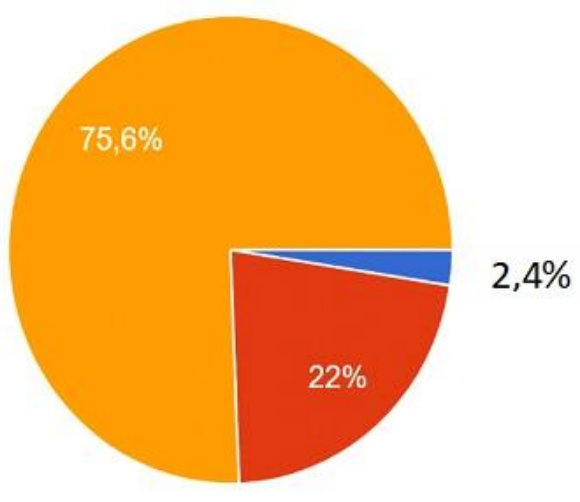

Federal

Estadual

Municipal

Fonte: Elaborado pelos autores com base nos dados da pesquisa (2020).

Identificamos, no Gráfico 3, um quantitativo expressivamente superior de profissionais de educação que participaram deste estudo atuando efetivamente na rede municipal da cidade do Rio de Janeiro.

Na seção a seguir, apresentamos alguns tópicos abordados nas perguntas do questionário, os quais nos permitem identificar como os professores percebem as ações educacionais, em suas respectivas redes de ensino, em plena pandemia de Covid-19, de abril a julho de 2020. Seguimos, para tanto, os seguintes tópicos para a realização da análise: informações gerais sobre as atividades executadas pelos profissionais de educação durante o período da pandemia; realização/participação dos profissionais em algum curso ou capacitação em EaD; e existência de apoio da rede de ensino aos profissionais para a realização de atividades remotas próprias da docência.

\section{Atividades executadas pelos profissionais de educação durante a pandemia}

Para este tópico, evidenciamos, dentre os profissionais que participaram da pesquisa, aqueles que, de alguma forma, continuaram a realizar atividades próprias de seu ofício durante o período de pandemia. No gráfico abaixo, podemos verificar o percentual daqueles que continuaram suas atividades e daqueles que tiveram suas atividades interrompidas. Não tratamos aqui qual fator levou a uma interrupção total das atividades daqueles que manifestaram isso durante a pesquisa, pois sabemos que podem ser inúmeras razões e, para analisá-las, seria necessário um trabalho específico. 
Gráfico 4 - Percentual dos profissionais participantes da pesquisa que tiveram suas atividades interrompidas durante a pandemia

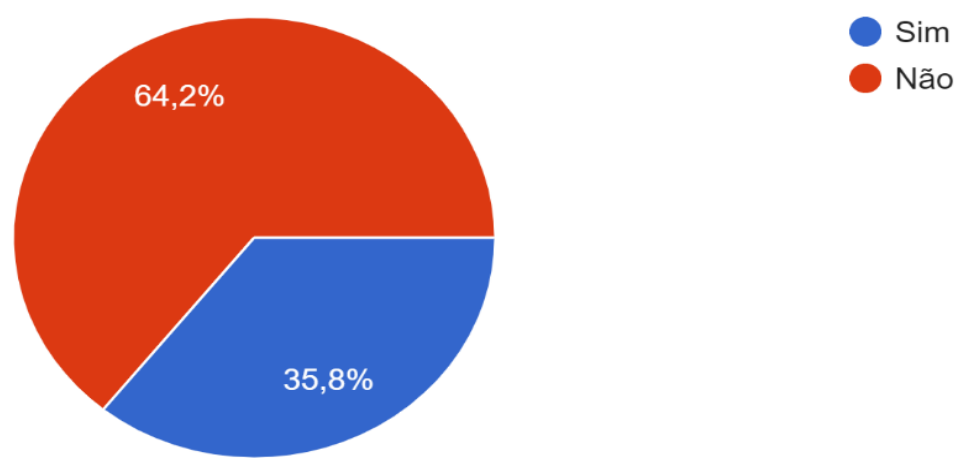

Fonte: Elaborado pelos autores com base nos dados da pesquisa (2020).

A interpretação dos dados contidos no Gráfico 4 leva-nos a uma percepção positiva diante da maior parte de respostas que indica a não interrupção das atividades docentes. Contudo, quando cruzamos esses dados com informações específicas dos segmentos nos quais os professores atuam (Gráfico 5), identificamos que o maior percentual de interrupção de atividades se deu justamente no Ensino Médio e na Educação Infantil, $52 \%$ e $42 \%$, respectivamente. Isso significa dizer que a entrada e a saída do processo de escolarização da Educação Básica sofreram maior impacto, e as consequências disso podem prejudicar ainda mais o acesso e a continuidade dos estudos de milhares de crianças e jovens no Brasil.

Gráfico 5 - Percentual dos professores participantes da pesquisa que tiveram suas atividades interrompidas durante a pandemia

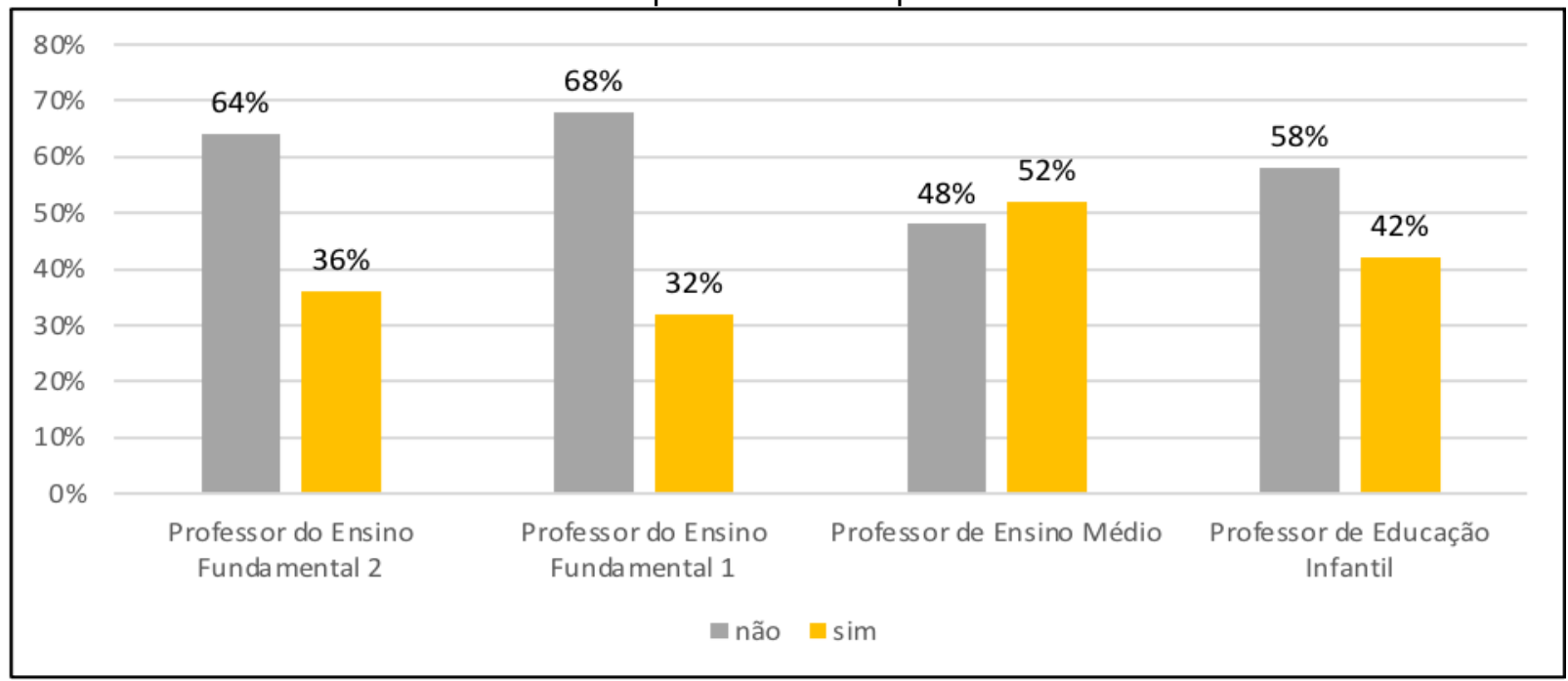

Fonte: Elaborado pelos autores com base nos dados da pesquisa (2020).

Educ. Form., Fortaleza, v. 6, n. 3, e5412, set./dez. 2021

DOI: https://doi.org/10.25053/redufor.v6i2.5412

https://revistas.uece.br/index.php/redufor/index 
É oportuno registrar que o entendimento de atividades interrompidas, para efeitos deste trabalho, é o de uma interrupção completa, isto é, sem nenhuma atividade de interação com os alunos, inclusive de maneira remota ou virtual. Assim, mesmo os percentuais mais baixos aqui identificados, 32\% para o Ensino Fundamental 1 e $36 \%$ para o Ensino Fundamental 2, no universo que engloba escolas de três entes federativos no Rio de Janeiro, representam uma quantidade expressiva de crianças e jovens impossibilitados de dar continuidade à sua escolarização.

No que tange à participação das redes de ensino para a manutenção das atividades dos professores através do modelo remoto, registramos abaixo as respostas dos docentes ao questionário, ou seja, os docentes nos indicam como as redes agiram e estão agindo para manter uma interação mínima entre professores e alunos durante o período de isolamento social.

Gráfico 6 - Atividades de EaD de todos os profissionais da escola

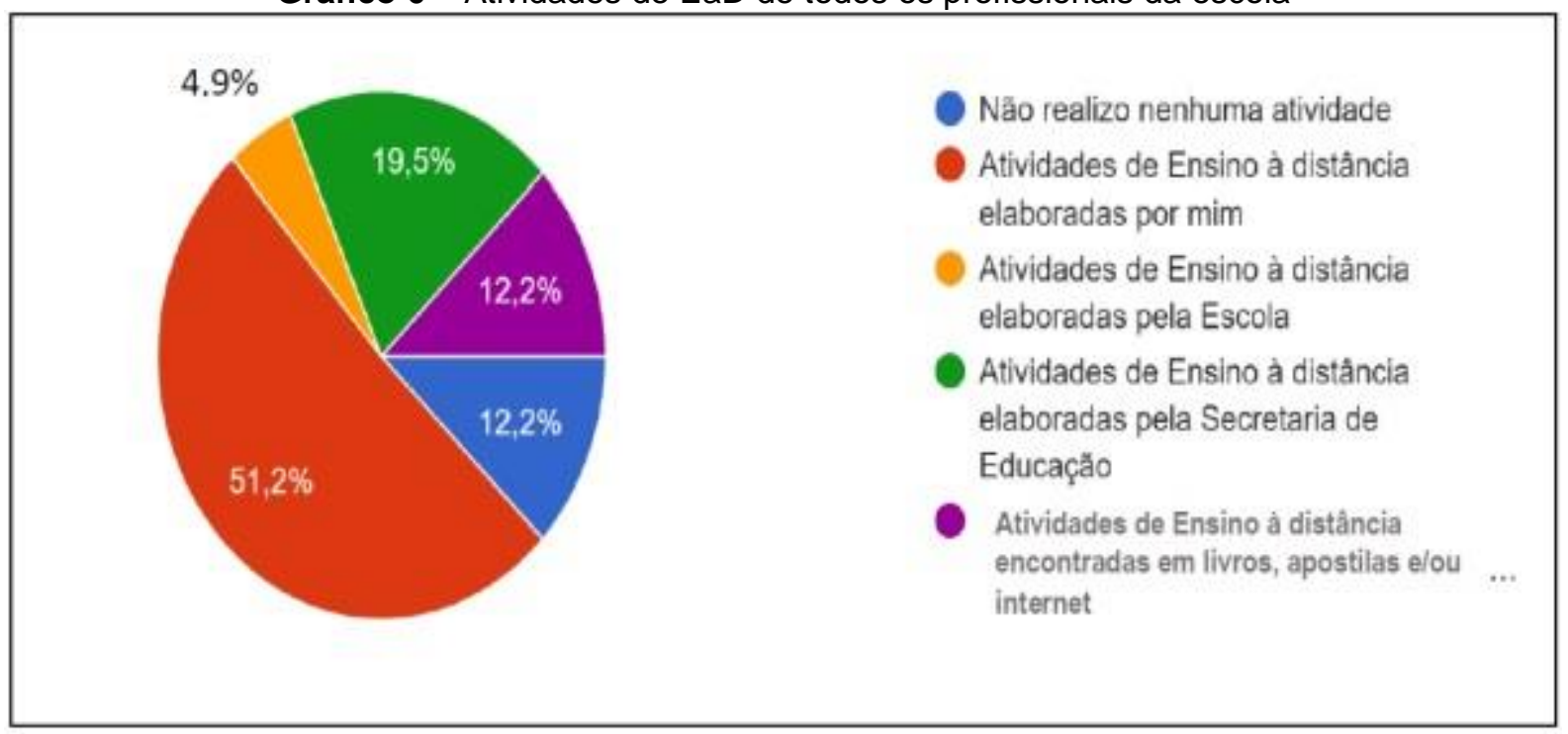

Fonte: Elaborado pelos autores com base nos dados da pesquisa (2020).

O Gráfico 6 permite-nos verificar que praticamente a metade dos professores que fizeram atividades durante o período de isolamento social realizou tais ações por conta própria: $51 \%$. Já a não realização ou a efetivação de atividades elaboradas pelas escolas, Secretarias de Educação ou mesmo retiradas da internet, livros ou apostilas representam, juntas, a outra metade das respostas. Isso nos leva a crer que as experiências escolares das instituições públicas de ensino onde atuam os sujeitos da 
presente pesquisa indicam uma bifurcação das ações docentes, o que tende a piorar ainda mais as desigualdades no complexo e heterogêneo sistema público de ensino.

Por outro lado, para melhor compreensão das respostas dos professores em relação às atividades realizadas, optamos por trazer informações específicas, conforme Tabela 1, e atentamos para o fato de que o número de professores com atividade em sala de aula foi de 102.

Tabela 1 - Atividades de EaD dos professores

\begin{tabular}{c|c|c|c|c|c}
\hline & $\begin{array}{c}\text { Professor de } \\
\text { Educação } \\
\text { Infantil }\end{array}$ & $\begin{array}{c}\text { Professor } \\
\text { de Ensino } \\
\text { Médio }\end{array}$ & $\begin{array}{c}\text { Professor de } \\
\text { Ensino } \\
\text { Fundamental } \\
\mathbf{1}\end{array}$ & $\begin{array}{c}\text { Professor de } \\
\text { Ensino } \\
\text { Fundamental } \\
\mathbf{2}\end{array}$ & Total \\
\hline $\begin{array}{c}\text { Atividades de EaD } \\
\text { elaboradas pela } \\
\begin{array}{c}\text { Secretaria de } \\
\text { Educação }\end{array}\end{array}$ & 1 & 3 & 5 & 9 & $18(17,64 \%)$ \\
\hline $\begin{array}{c}\text { Atividades de EaD } \\
\text { elaboradas por mim }\end{array}$ & 8 & 15 & 17 & 18 & $58(56,86 \%)$ \\
\hline $\begin{array}{c}\text { Atividades de EaD } \\
\text { encontradas em } \\
\text { livros, apostilas e/ou } \\
\text { internet }\end{array}$ & 0 & 3 & 7 & 4 & $14(13,72 \%)$ \\
\hline Não realizo nenhuma \\
atividade
\end{tabular}

Fonte: Elaborada pelos autores com base nos dados da pesquisa (2020).

Como já observado anteriormente, o percentual de professores que desenvolveu suas atividades junto aos alunos, através do ensino a distância de maneira autônoma, corresponde a mais da metade dos participantes da pesquisa. Detemo-nos ainda ao fato de que somente $17,64 \%$ dos respondentes indicaram que as Secretarias de Educação contribuíram com alguma atividade para a atuação dos docentes durante a pandemia nos meses de abril a julho de 2020 .

\section{0 apoio da rede de ensino para os profissionais nas atividades durante a pandemia}

Conforme já mencionado neste estudo, o isolamento social se tornou o mecanismo de proteção recomendado para que as pessoas não se contaminassem com a Covid-19 e tal situação tornou inviável a continuidade das atividades escolares de maneira presencial. Diante desse cenário, os Conselhos de Educação estimularam, 
mesmo que de forma temporária, que as atividades fossem realizadas na modalidade de ensino a distância. Logo, esta pesquisa buscou identificar como os professores perceberam o curso das referidas orientações nos tópicos anteriores.

Para tanto, buscamos evidenciar como os profissionais de Educação Básica, em especial, os professores, desenvolveram suas atividades nesse contexto de isolamento social. A partir de agora, nosso olhar se volta para as ações específicas das redes de ensino, evidenciando o que foi encontrado, junto aos participantes da pesquisa, sobre suas percepções em relação ao que a rede de ensino fez, em forma de apoio, para que as atividades educacionais prosseguissem.

Com o objetivo de melhor compreender essa dimensão de análise, optamos por apresentar três questões relacionadas ao ensino remoto e ao apoio das redes de ensino aos profissionais de educação. A primeira se refere ao conhecimento atual dos profissionais de educação sobre EaD.

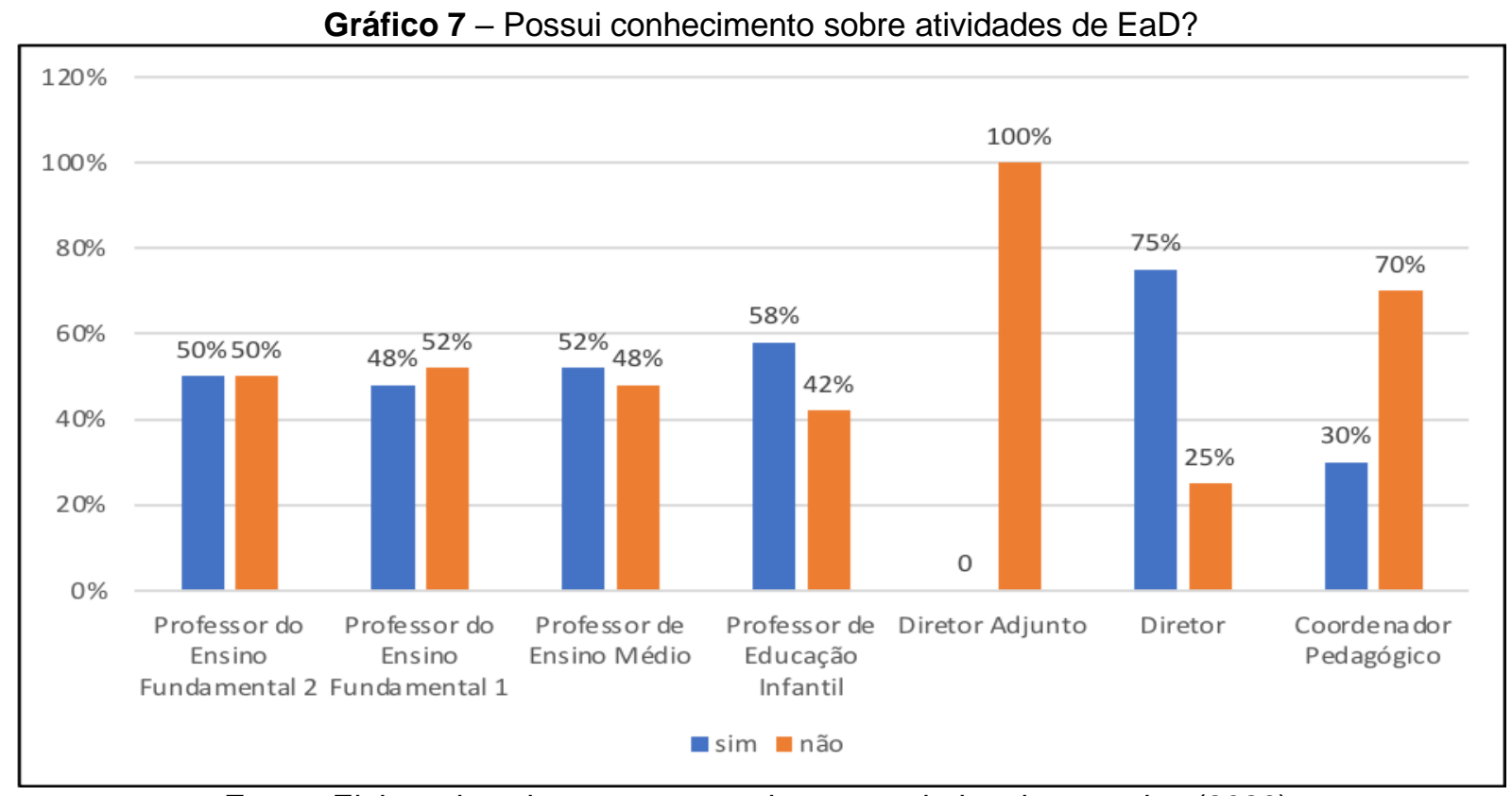

Fonte: Elaborado pelos autores com base nos dados da pesquisa (2020).

A segunda questão está relacionada ao recebimento de capacitação ou curso que em seu conteúdo transmitisse conhecimentos para o desenvolvimento de atividades de $\mathrm{EaD}$ aos profissionais de educação, desenvolvida(o) por suas redes de ensino. 
Gráfico 8 - Possui curso ou capacitação para realizar atividades de EaD fornecido por sua rede de ensino?

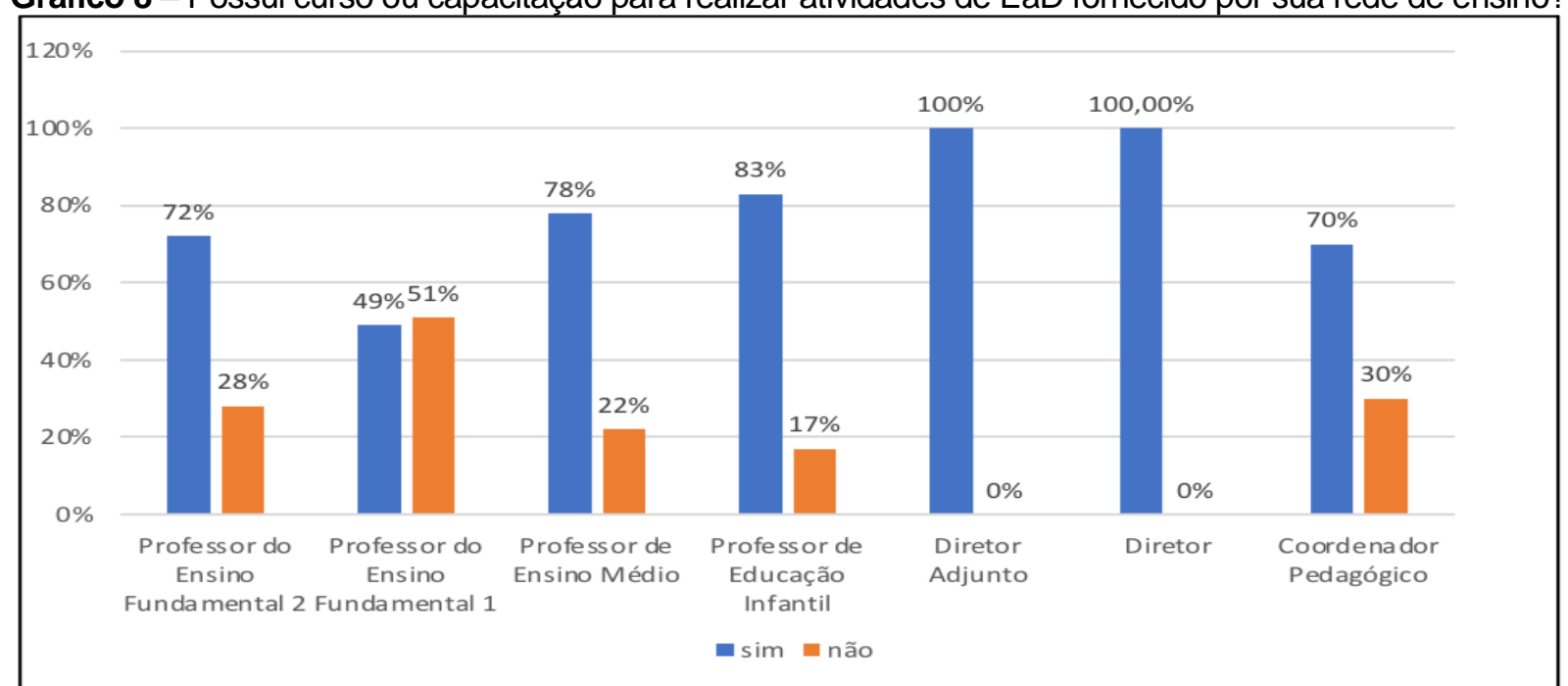

Fonte: Elaborado pelos autores com base nos dados da pesquisa (2020).

Embora pareça contraditório, se compararmos os Gráficos 7 e 8, observamos que as redes de ensino ofereceram cursos ou capacitação para os profissionais das escolas públicas, com vistas à atuação em EaD. Apenas os profissionais do Ensino Fundamental 1 apontaram um percentual expressivo (51\%) de não oferta de capacitação para a realização de atividades de EaD.

Por fim, apresentamos a percepção dos profissionais de educação a respeito do efetivo empenho de sua rede de ensino em manter os alunos com atividades educativas durante o período de "isolamento social".

Gráfico 9 - Sua rede se empenha em manter os alunos com atividades educativas durante o período de

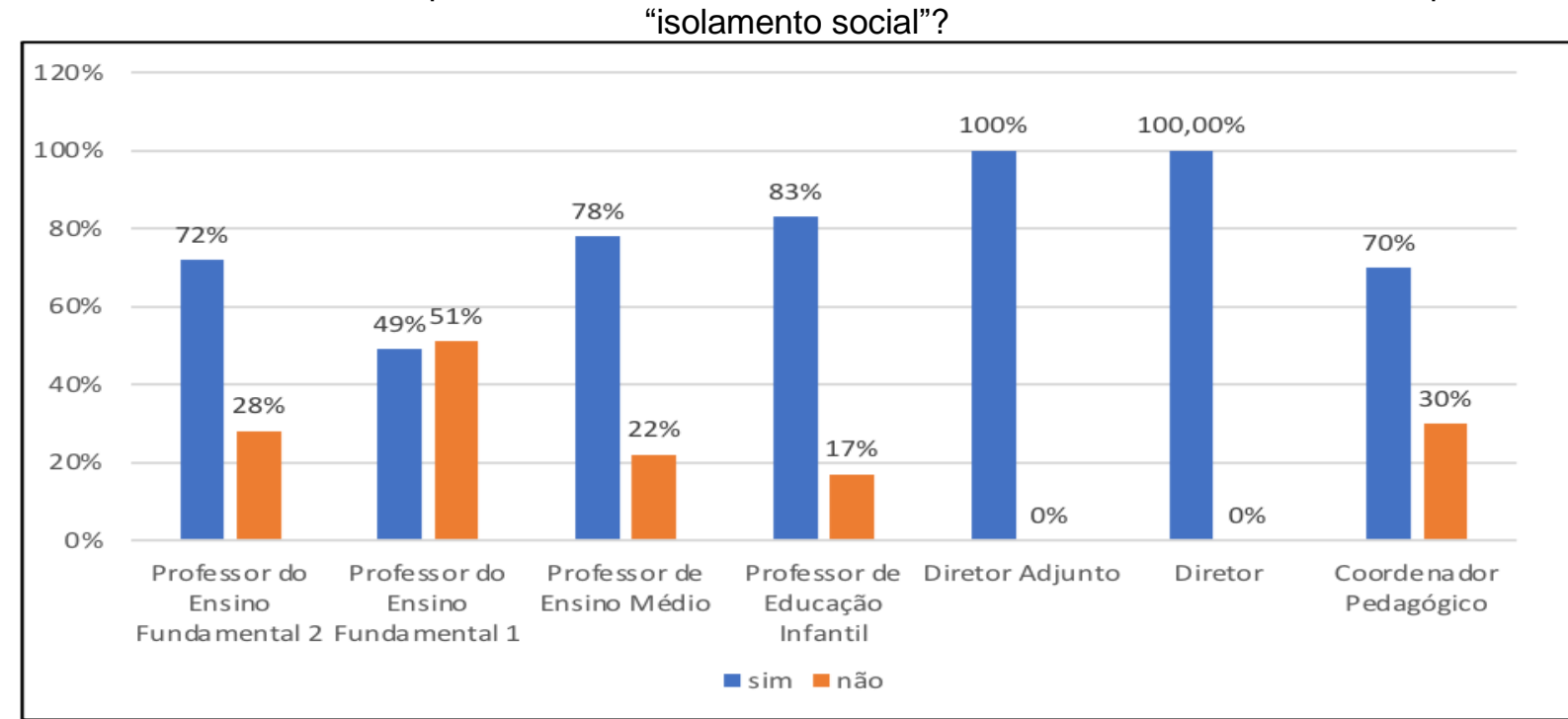

Fonte: Elaborado pelos autores com base nos dados da pesquisa (2020).

Educ. Form., Fortaleza, v. 6, n. 3, e5412, set./dez. 2021

DOI: https://doi.org/10.25053/redufor.v6i2.5412

https://revistas.uece.br/index.php/redufor/index 
Com o Gráfico 9, encerramos a apresentação dos dados colhidos através da pesquisa realizada. Inferimos que grande parte dos professores respondentes percebe esforços de suas respectivas redes de ensino na manutenção de atividades educativas para os alunos durante a pandemia.

Agora, avançaremos para uma análise mais detalhada dos dados, buscando realizar as correlações possíveis com a finalidade de traçarmos um perfil do que buscamos como objetivo deste estudo.

\title{
6 Análise de dados
}

Para o presente estudo, a abordagem utilizada buscou, dentro da amostra produzida, representar como estariam as percepções sobre políticas e ações públicas na educação pública da cidade do Rio de Janeiro durante o "isolamento social", que teve origem em razão do combate à Covid-19.

Consoante Silvano (2016, p. 100), a pesquisa quantitativa é importante para a tentativa de uma percepção da realidade de forma neutra, conforme mencionam a seguir:

\begin{abstract}
A pesquisa voltada para a abordagem quantitativa é sequencial e comprobatória, isso significa que uma fase acontece depois da outra e que internamente em cada fase se avalia o processo. Vale lembrar que, apesar da rigorosidade, é possível redefinir alguma fase. Esse tipo de pesquisa compreende que a realidade não se modifica por causa das observações e medições realizadas pelo pesquisador, devendo sua posição ser neutra, salienta-se que não há interação física nem psicológica entre o pesquisador e o fenômeno, mantendo o distanciamento, uma separação deliberada, ou seja, sem envolvimento.
\end{abstract}

Dessa maneira, iniciamos as análises evidenciando o contido no Gráfico 1, ou seja, o percentual dos profissionais de educação que atuam diretamente como professores em sala de aula (83\%) é bastante significativo para o que se almeja com esta pesquisa e, de certo modo, traz a percepção daqueles que estão efetivamente atuando em contato direto com os alunos em suas atividades diárias. Se considerarmos o cenário em que esse grande percentual de docentes se encontra, podemos inferir que nele tudo pode ocorrer, no qual, diante do desconhecido, maiores desafios se impõem. Em um tempo em que a educação altera seu processo de "ensinar e aprender", em que o espaço coletivo de interação é substituído pelo distanciamento necessário, muitas 
coisas estão mudando rapidamente e outras tantas mudarão. Sobre esse fato, Azevêdo (2020, p. 14) assim se posiciona:

\begin{abstract}
Agora, com o distanciamento físico compulsório, dado pela pandemia, a demanda de se manter os processos pedagógicos 'vivos', ocorre de que os laços com o(a)s educando(a)s precisam ser (r)estabelecidos, sob novos formatos. $O$ que antes era contingencial, superficial, agora emerge como imprescindível, estratégico. Dimensionar e planejar como desenvolver nosso trabalho frente a uma realidade tão complexa e delicada para nossos educandos nunca se colocou como um desafio tão premente quanto nos dias que correm.
\end{abstract}

Em avanço, nos Gráficos 2 e 3, observamos o predomínio de profissionais de educação com mais de dez anos de atividade na educação pública e também fazendo parte da rede de ensino do município do Rio de Janeiro. Ousamos afirmar ainda que os sujeitos da presente pesquisa são majoritariamente professores que atuam na concretude da sala de aula. Tal caracterização nos leva a inferir que as respostas ao questionário estão impregnadas de "saberes-fazeres" da docência de quem conhece o chão da escola pública. Assim, apostamos em percepções de professores imersos no universo educacional, mas que se encontram frente ao inesperado contexto de uma grave crise sanitária mundial.

Podemos evidenciar com isso que não há profissionais "totalmente" inexperientes e que a pesquisa sofreu um grande impacto das percepções dos profissionais de rede de educação municipal da cidade do Rio de Janeiro, que, devido ao atual cenário, possivelmente não deve ser muito diferente de tudo que esteja ocorrendo na educação brasileira ou, conforme Kohan (2020, p. 57):

\footnotetext{
Na educação brasileira, o embate é manifesto. Por um lado, existe a cobrança do MEC para que todas as escolas continuem o normal pedagógico na forma de $\mathrm{EaD}$ com os argumentos de não prejudicar, atrasar ou desfavorecer os estudantes. Ao mesmo tempo, muitos estudantes e professores não têm as condições mínimas (acesso à internet, equipamentos e ambientação) para seguir sua vida educativa online. A pandemia tem, nesse sentido, colocado abertamente a mazela da desigualdade endêmica neste país.
}

Após, no Gráfico 4, registramos os profissionais de educação que tiveram totalmente suas atividades interrompidas devido à Covid-19. O percentual de 35,8\% é bastante expressivo, o qual traz uma análise global dos diversos atores dentro da escola. Assim, para especificarmos melhor esta informação com os professores em atuação direta nas salas de aula, houve a produção do Gráfico 5, que registra um dado bastante 
preocupante, à medida que, em todas as modalidades de ensino, mais de $30 \%$ daqueles profissionais tiveram suas atividades totalmente interrompidas, com ênfase nos professores de Ensino Médio, cuja parcela acima de 50\% teve suas atividades interrompidas.

Mesmo com as limitações da pesquisa, a sinalização de que, no geral, mais de $30 \%$ dos professores tiveram suas atividades totalmente suspensas demonstra que o impacto no processo educacional pode ser bastante grave no futuro e que tal situação caminha, inclusive, na afetação dos direitos públicos do cidadão, pois, como mencionam Oliveira e Souza (2020, p. 18):

\begin{abstract}
Neste sentido, o sistema educacional conhecido como tradicional, assim como toda e qualquer atividade de outra área na sociedade, teve que parar. Até quando vai durar essa parada obrigatória ninguém sabe, mas ela já tem promovido amplas discussões no sentido de garantir aos estudantes o direito à Educação, conforme preconiza a Constituição Federal (BRASIL, 1988), que Ihes foi abruptamente retirado, ou melhor, interrompido por motivos de força maior, ainda que ela seja invisível.
\end{abstract}

No Gráfico 6, registramos as atividades de $\mathrm{EaD}$ realizadas pelos profissionais participantes da pesquisa e aqui cabe evidenciar que as informações se referem a atividades de qualquer tipo que ocorram de forma remota e/ou não configurem interação com os alunos de forma presencial na unidade escolar. Nesta análise, encontramos como um fator relevante o percentual de mais de $50 \%$ de profissionais que desenvolveram suas próprias atividades, uma constatação que, em princípio, devemos considerar como de autonomia na atividade dos profissionais de educação, ou seja, mais da metade elaboram suas próprias atividades. No entanto, observamos a baixa participação das escolas, como grupo conjunto atuante nas mesmas atividades (4,9\%), fato que pode evidenciar que as escolas pouco participaram ou contribuíram com os seus profissionais na elaboração e dinamização de materiais e conteúdo para os alunos.

O mencionado no parágrafo anterior fica mais evidente quando avançamos para a análise específica dos professores com relação ao mesmo assunto, conforme Tabela 1, pois percebemos que mais da metade dos professores das diversas etapas de ensino da Educação Básica realizam suas atividades de maneira autônoma. Tal indicativo se correlaciona com o conteúdo do Gráfico 7 , basicamente em percentuais, dado que demonstra uma proximidade da autonomia dos professores em realizar suas atividades através da EaD com o conhecimento sobre essas atividades. Dessa forma, os docentes buscaram agir de maneira autônoma, usando o conhecimento que possuem, uma vez

Educ. Form., Fortaleza, v. 6, n. 3, e5412, set./dez. 2021

DOI: https://doi.org/10.25053/redufor.v6i2.5412

https://revistas.uece.br/index.php/redufor/index 
que o enraizamento das tecnologias digitais no cotidiano é um fato ou, como definem Cani et al. (2020, p. 35):

\begin{abstract}
Refletimos, aqui, que a proeminência das tecnologias digitais nos ajuda a pensar sobre como elas estão se cristalizando em nosso cotidiano a ponto de, em pouco tempo, nos darmos conta de que não poderemos mais deixar de incluí-las na educação formal. Sob essa perspectiva, os professores partilham conhecimentos e produzem novos sentidos para suas disciplinas, inserindo-se nos princípios norteadores da BNCC (Base Nacional Comum Curricular) - quanto às TDIC (Tecnologias Digitais de Informação e Comunicação), que estão cada vez mais presentes na vida dos indivíduos -, ao praticarem o uso de diferentes linguagens (digital, visual, sonora, verbal e textual).
\end{abstract}

Temos ainda que, dentro do percentual de professores que realizam suas atividades relacionadas ao ensino a distância, com autonomia, conforme Tabela 1, que 74\% manifestaram possuir algum curso ou capacitação relacionado à EaD fornecido por sua rede de ensino, fato que se correlaciona diretamente com o apresentado pelo Gráfico 8. Trata-se de um bom número e demonstra que, em algum momento, as redes de ensino se preocuparam em manter seus professores atualizados com as novas Tecnologias Digitais de Informação e Comunicação (TDIC), haja vista que, na maioria dos casos, os professores não possuem em sua formação inicial disciplinas que se dediquem aos conhecimentos e habilidades para lecionar utilizando tais tecnologias. Tal situação é evidenciada por Abreu, Novaes e Zarro (2020, p. 20-21) em uma pesquisa que trata sobre os desafios na formação de professores para a atuação na EaD:

\begin{abstract}
Considerando o universo pesquisado, é possível concluir que a formação acadêmica clássica não contempla ou reconhece como potencialidade o ensino a distância. Tal fato gera para os professores que atuam nessa modalidade uma dificuldade extra, uma vez que o ensino a distância é realidade instalada na Educação Nacional. Uma formação que não inclua nenhum elemento nas discussões formais nas Universidades dos cursos de licenciatura sobre o ensino em EaD não instrumentaliza adequadamente o fazer do profissional. Com isso, dado o exposto foi possível notar que entre os professores pesquisados a grande maioria teve que recorrer a outros meios para complementar sua formação, embora a EaD faça parte da realidade mais imediata de alocação profissional.
\end{abstract}

Da mesma maneira, Oliveira, Araújo e Silva (2020, p. 7) avançam com a necessidade de se reconstruir uma formação de professores mais atual:

\footnotetext{
Assim, o professor sujeito/ator que produz e mobiliza saberes tem diante de si classes repletas de alunos/sujeitos/atores. Há, portanto, algo de específico na ação docente, um conjunto de comportamentos, conhecimentos, destrezas, atitudes e valores que constituem a especificidade de ser professor. Por isso, urge a necessidade de se repensarem os programas de formação de professores.
}

Educ. Form., Fortaleza, v. 6, n. 3, e5412, set./dez. 2021

DOI: https://doi.org/10.25053/redufor.v6i2.5412

https://revistas.uece.br/index.php/redufor/index 
Por fim, temos o Gráfico 9, que se iguala nos percentuais ao Gráfico 8, fato que representa uma mera coincidência, mas que traz uma característica importante: 0 posicionamento dos profissionais que formam a gestão das unidades escolares (diretor e diretor adjunto). Esse grupo apresenta 100\% de posicionamento a favor da rede de ensino de que fazem parte seus membros, exatamente nos dois questionamentos que se referem diretamente à ação de tais redes, e entendemos como posicionamentos naturais pela posição que tais profissionais ocupam na gestão da escola, mas é importante destacá-los, à medida que podem ser posicionamentos defensivos, mesmo com garantias de anonimato da pesquisa.

\section{Considerações finais}

A partir do objetivo deste trabalho e com as limitações a ele impostas pela própria forma de buscar as informações necessárias, com o fim de aproximarmos o mais possível da realidade sobre a percepção dos profissionais de educação da cidade do Rio de Janeiro com relação às ações de suas redes de ensino durante a pandemia da Covid-19, a análise dos dados nos permite destacar alguns elementos importantes que contribuíram para compreendermos melhor a situação pesquisada.

Observamos que o cenário de isolamento social imposto pela pandemia foi tratado de maneira semelhante em todas as redes de ensino que existem na cidade (federal, estadual e municipal), ou seja, suspendendo as aulas presencias em todas as escolas. Entretanto, a autonomia existente para o gerenciamento das redes não evidenciou uma uniformidade na condução de ações para a continuidade das aulas de maneira não presencial, e tal fato passou a ser mais um problema além da pandemia.

O grupo de participantes da pesquisa, com preponderância de profissionais da rede municipal de educação da cidade do Rio de Janeiro, apesar de aparentemente possuir uma boa experiência profissional, especificamente ligada ao tempo de serviço, teve, de maneira geral, um percentual acima de 30\% de profissionais que interromperam totalmente suas atividades durante a pandemia, fato que pode ser considerado muito preocupante. Além disso, percebemos que o trabalho realizado "a distância", através das TDIC, por aqueles que continuaram suas atividades foi feito, também na maioria, de 
forma autônoma, sem o apoio da escola, revelando uma ação desconexa entre escola e professores.

Mesmo que a percepção dos professores reconheça a efetiva participação de suas redes de ensino para que não ocorra interrupção das atividades com os alunos e que essas mesmas redes tenham, de alguma forma, contribuído com capacitação em EaD para a formação continuada de seus profissionais, encontramos um contexto de atividades suspensas e atividades autônomas, possivelmente sem direcionamento, beirando uma falta de controle, de planejamento e de ações coordenadas que deixam suas marcas hoje e poderão deixar sequelas no futuro pós-pandemia.

Ainda sobre o foco acima, devemos levar em consideração que um possível hiato na formação dos professores para trabalhar com os recursos de TDIC ficou transparente, situação que se refletiu sobremaneira no percentual dos profissionais que interromperam totalmente suas atividades. É importante apurar e aprimorar o potencial dos futuros professores em situações que poderão ser caracterizadas como as da atual pandemia, haja vista o que mencionam Kondrashova et al. (2020, p. 5):

\footnotetext{
O potencial criativo de futuros professores como uma educação pessoal complexa combina, em sua estrutura, componentes motivacionais, operacionais, pessoais e avaliativos que refletem o conjunto de habilidades e qualidades pessoais, estados psicológicos, conhecimentos, competências e habilidades necessárias para soluções criativas a problemas pedagógicos na futura atividade profissional.
}

Por fim, acreditamos que esta pequena contribuição, exploratória e inicial, possa permitir outros caminhos para estudos mais aprofundados sobre os impactos da Covid-19 no sistema educacional brasileiro, explorando novos objetos e, inclusive, avançando para conclusões mais definitivas que possam permitir legados importantes e preparo para situações que sejam semelhantes.

\section{Referências}

ABREU, E. T.; NOVAES, M. A.; ZARRO, M. I. M. Desafios na formação de professores para atuação na EaD. Revista Paidéi@, Santos, v. 12, n. 21, p. 1-24, 2020. Disponível em: http://periodicos.unimesvirtual.com.br/index.php/paideial. Acesso em: 15 abr. 2020.

AZEVÊDO, A. A. O que a pandemia interpela a professores e professoras. Natal: Feitoemcasa, 2020. 
BRASIL. Parecer do Conselho Nacional de Educação/Conselho Pleno no 05/2020, de 28 de abril de 2020. Reorganização do Calendário Escolar e da possibilidade de cômputo de atividades não presenciais para fins de cumprimento da carga horária mínima anual, em razão da Pandemia da COVID-19. Diário Oficial [da] República Federativa do Brasil, Poder Executivo, Brasília, DF, 1ํ jun. 2020.

CAMPOS, G. W. S. O pesadelo macabro da Covid-19 no Brasil: entre negacionismos e desvarios. Trabalho, Educação e Saúde, Rio de Janeiro, v. 18, n. 3, e00279111, 2020. Disponível em: http://www.revista.epsjv.fiocruz.br/index.php?area=periodico. Acesso em: 10 jul. 2020.

CANI, J. B. et al. Educação e Covid-19: a arte de reinventar a escola mediando a aprendizagem "prioritariamente" pelas TDIC. Revista IFES Ciência, Vitória, v. 6, n. esp., n. 1, p. 23-39, 2020. Disponível em: https://ojs.ifes.edu.br/index.php/ric/article/view/713/484. Acesso em: 26 jul. 2020.

DOXSEY, J. R.; DE RIZ, J. Metodologia da pesquisa científica: apostila. Vila Velha: ESAB, 2002-2003. Disponível em: https://cafarufri.files.wordpress.com/2009/05/metodologia pesquisa cientifica.pdf. Acesso em: 26 jul. 2020.

GAUTHIER, C.; BISSONNETTE, S.; BOCQUILLON, H. Instruir ou deslumbrar os alunos?: reflexão crítica sobre a ideia de que "precisamos variar o nosso ensino". Educação \& Formação, Fortaleza, v. 6, n. 3, e5404, 2021. Disponível em: https://revistas.uece.br/index.php/redufor/article/view/5404. Acesso em: 29 jun. 2021.

KOHAN, W. O. Formação inventiva de professores em tempos de pandemia: o que um louco lúcido nos convida a pensar e escrever?. Mnemosine, Rio de Janeiro, v. 16, n. 1, p. 53-66, 2020. Disponível em: https://www.e-publicacoes.uerj.br/index.php/mnemosine/. Acesso em: 12 abr. 2020.

KONDRASHOVA, L. V. et al. Desenvolvimento do potencial criativo de futuros professores: estratégia para melhorar a qualidade do ensino superior pedagógico. Educação \& Formação, Fortaleza, v. 5, n. 3, p. 1-15, 2020. Disponível em: https://revistas.uece.br/index.php/redufor/article/view/3292. Acesso em: 29 jun. 2021.

MACEDO, Y. M.; ORNELLAS, J. L.; BOMFIM, H. F. Covid-19 no Brasil: o que se espera para população subalternizada?. Revista Encantar: Educação, Cultura e Sociedade, Bom Jesus da Lapa, v. 2, p. 1-10, 2020. Disponível em:

https://www.revistas.uneb.br/index.php/encantar/article/view/8189/. Acesso em: 12 abr. 2021.

OLIVEIRA, H. V.; SOUZA, F. S. Do conteúdo programático ao sistema de avaliação: reflexões educacionais em tempos de pandemia (Covid-19). Boletim de Conjuntura, Boa Vista, v. 2, n. 5, p. 15-24, 2020. Disponível em: https://revista.ufrr.br/boca/issue/view/284. Acesso em: 20 jun. 2020. 
OLIVEIRA, S. M. S.; ARAÚJO, F. M. L.; SILVA, C. D. M. A prática como lócus de produção de saberes: vozes de professores sobre formação inicial e práticas escolares cotidianas. Educação \& Formação, Fortaleza, v. 6, n. 1, e2885, 2020. Disponível em: https://revistas.uece.br/index.php/redufor/article/view/2885. Acesso em: 29 jun. 2021.

\section{RIO DE JANEIRO. Governo do Estado do Rio de Janeiro. Deliberação do Conselho} Estadual de Educação no 376, de 23 de março de 2020. Orienta as Instituições integrantes do Sistema Estadual de Ensino do estado do Rio de Janeiro sobre o desenvolvimento das atividades escolares não presenciais, em caráter de excepcionalidade e temporalidade, enquanto permanecerem as medidas de isolamento previstas pelas autoridades estaduais na prevenção e combate ao Coronavírus - Covid-19. Disponível em: http://www.cee.ri.gov.br/deliberacoes. Acesso em: 10 jun. 2020.

RIO DE JANEIRO. Prefeitura da cidade do Rio de Janeiro. Deliberação do Conselho Municipal de Educação no 39, de 02 de abril de 2020. Orienta as instituições do Sistema Municipal de Ensino do Rio de Janeiro sobre a realização de atividades escolares em regime especial domiciliar, em caráter excepcional, no período em que permanecerem em isolamento social fixado pelas autoridades municipais e pela comunidade médico-científica, em razão da necessidade de prevenção e combate ao Covid-19 -

Coronavírus. Disponível em:

http://www.rio.ri.gov.br/web/sme/exibeconteudo?id=1122731. Acesso em: $1^{\circ}$ jun. 2020.

SANTANA FILHO, M. M. Educação geográfica, docência e o contexto da pandemia Covid-19. Revista Tamoios, São Gonçalo, v. 16, n. 1, p. 3-15, 2020. Disponível em: https://www.e-publicacoes.ueri.br/index.php/tamoios. Acesso em: 10 jul. 2020.

SILVA, G. F. Das ocupações de escolas ao governo Bolsonaro: desafios à educação pública no Brasil contemporâneo. In: ENCONTRO DE HISTÓRIA DA ANPUH-RIO, 19., 2020, Rio de Janeiro. Anais [...]. Rio de Janeiro: Anpuh, 2020. Disponível em:

https://www.encontro2020.rj.anpuh.org/anais/trabalhos/trabalhosaprovados. Acesso em: 12 abr. 2021.

SILVANO, A. M. C. Possibilidades e limites da abordagem quantitativa na pesquisa em Educação. Educação, Escola e Sociedade, Montes Claros, v. 9, n. 9, p. 95-110, 2016. Disponível em: https://www.periodicos.unimontes.br/index.php/rees/article/view/286. Acesso em: 20 abr. 2020.

\footnotetext{
Jairo Campos dos Santos, Prefeitura da cidade do Rio de Janeiro, Secretaria Municipal de Fazenda do Rio de Janeiro

i. (Dhttps://orcid.org/0000-0003-1915-0343

Doutorado em Educação, na linha de Pesquisa Políticas e Instituições Educacionais - PPGE - UFRJ. Mestrado em Gestão e Estratégia e Negócios - PPGEN - UFRRJ. Especialização em Gestão da Administração Pública - UCB - Unesco. Especialização em Informática Educativa - UCB. Graduação em Matemática - UCB. Graduação em Administração - UniMSB. Analista de Planejamento e Orçamento da Secretaria Municipal de Fazenda da cidade do Rio de Janeiro - SMF - PCRJ.

Contribuição de autoria: Escrita, coleta de dados e análise dos dados.

Lattes: http://lattes.cnpq.br/6081836037741039

E-mail: jairo06@uol.com.br
}

Educ. Form., Fortaleza, v. 6, n. 3, e5412, set./dez. 2021

DOI: https://doi.org/10.25053/redufor.v6i2.5412

https://revistas.uece.br/index.php/redufor/index 
Luiza Alves de Oliveira, Universidade Federal Rural do Rio de Janeiro, Programa de Pós-Graduação em Educação em Ciências e Matemática

iD https://orcid.org/0000-0002-5974-3947

Doutora em Educação pela Universidade Federal do Rio de Janeiro (UFRJ, 2011), mestra em Linguística pela UFRJ (2004) e graduada em Letras pela Universidade do Estado do Rio de Janeiro (UERJ, 1989). Atualmente é professora adjunta da Universidade Federal Rural do Rio de Janeiro (UFRRJ) e docente do quadro permanente do Programa de Pós-Graduação em Educação em Ciências e Matemática (PPGEduCIMAT) da UFRRJ.

Contribuição de autoria: Escrita, análise dos dados e revisão do texto.

Lattes: http://lattes.cnpq.br/8903633990618166

E-mail: luiza.aoliveira@uol.com.br

Editora responsável: Lia Machado Fiuza Fialho Pareceristas ad hoc: Aparecida Zuin e Maria Vasconcelos

Como citar este artigo (ABNT):

SANTOS, Jairo Campos dos; OLIVEIRA, Luiza Alves de. Percepções sobre as ações das redes públicas de ensino durante a pandemia. Educ. Form., Fortaleza, v. 6, n. 3, e5412, 2021. Disponível em: https://revistas.uece.br/index.php/redufor/article/view/5412

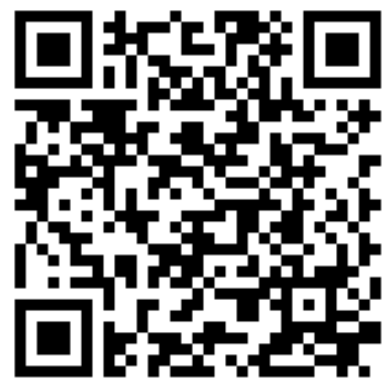

Recebido em 28 de abril de 2021.

Aceito em 28 de junho de 2021.

Publicado em 17 de julho de 2021.

Educ. Form., Fortaleza, v. 6, n. 3, e5412, set./dez. 2021

DOI: https://doi.org/10.25053/redufor.v6i2.5412

https://revistas.uece.br/index.php/redufor/index 